\section{Human dura mater permeability}

To the Editor:

I read with interest the paper by McEllistrem et al. ${ }^{1}$ The authors attempted to determine the effect of molecular weight and lipid solubility on drug diffusion from the epidural space to the spinal cord. They addressed this question by measuring drug flux through human dura mater in vitro. Unfortunately, the study has several shortcomings which would seem to render the authors' conclusions invalid:

1 The most important is that the authors measured drug flux through the dura mater only. We have previously shown that the arachnoid mater, which is composed of overlapping cells with frequent tight junctions, is the principal meningeal permeability barrier. ${ }^{2}$ Our study also demonstrated that the acellular dura mater is an unimportant meningeal diffusion "[the spinal arachnoid] ... is unlikely to pose an important barrier to diffusion." If the authors believe that the arachnoid is not the principal meningeal permeability barrier, then they need to explain why the water, electrolytes and glucose which make up the CSF are confined within the subarachnoid space. Clearly; it is because the arachnoid mater is highly permeable. If the dura mater were the principal meningeal permeability barrier, then CSF would freely diffuse through the arachnoid and collect beneath the dura mater in the subdural space. That this is not the case is very strong support of our experimental evidence that the arachnoid mater, not the dura mater, is the only important meningeal barrier. Thus the authors' data regarding diffusion through the dura mater would not appear to be applicable to movement of drugs through the intact spinal meninges.

2 The authors froze their tissue at $-70^{\circ} \mathrm{C}$ before study. However, they have not demonstrated that the proteins, glycolipids, proteoglycans, etc. which make up the dura mater and its ground substance behave normally after being frozen at this temperature. Thus, it is unclear if their data reflect the in vivo behaviour of the dura mater either.

3 The authors state that neither molecular weight nor lipid solubility are important in determining meningeal permeability. However, using an in vitro model which uses intact (dura, arachnoid and pia mater), live primate meningeal tissue, we previously demonstrated that lipid solubility is the only important determinant of meningeal permeability. ${ }^{3}$ The reason that lipid solubility is important is that movement through the lipid bilayers of the arachnoid mater cells is the rate-limiting step in meningeal diffusion.
4 The authors report drug flux, not "permeability" as stated in the manuscript. Flux is a measure of the rate of drug transfer (units of mass per unit time) and is therefore dependent on the concentration gradient across the tissue. Permeability takes concentration gradient into account and has units of distance per unit time. Thus, it is not surprising and not very informative that the authors found that drug flux is dependent on the initial concentration gradient across the tissue.

I applaud the authors' interest in this area of research. Clearly more work needs to be done before we fully understand the dynamics of epidural drug delivery. However, our understanding can be advanced only by use of models which are appropriate to the questions being addressed. I believe that the available experimental data indicate that the model employed by Dí. McEllistrem and co-workers is not appropriate to further our understanding of the dynamics of epidural drug delivery.

Christopher M. Bernards MD

Department of Anesthesiology

University of Washington

\section{REFERENCES}

1 McEllistrem RF, Bennington RG, Roth SH. In vitro determination of human dura mater permeability to opioids and local anaesthetics. Can J Anaesth 1993; 40: 165-9.

2 Bernards CM, Hill HF. Morphine and alfentanil permeability through the spinal dura, arachnoid, and pia mater of dogs and monkeys. Anesthesiology 1990; 73: 1214-9.

3 Bernards $C M$, Hill $\dot{H} F$. Physical and chemical properties of drug molecules governing their diffusion through the spinal meninges. Anesthesiology 1992; 77: 750-6.

\section{Negative arterial to end-tidal $\mathrm{CO}_{2}$ gradients in children}

\section{To the Editor:}

The paper by Campbell et al. ${ }^{\prime}$ is another important contribution to confirm that the recent developments in endtidal $\mathrm{CO}_{2}$ monitoring have made capnography in infants and children as reliable as in adults. However, I would like to make some comments.

First, the reliability of end-tidal $\mathrm{CO}_{2}\left(\mathrm{PETCO}_{2}\right)$ as sampled from the nasal cavity in awake infants, breathing spontaneously, has been evaluated previously and found to be a reliable estimate of $\mathrm{PaCO}_{2}{ }^{2-4}$ Dumpit and Brady designed a nasal catheter to sample end-tidal gas from the nostril in infants. ${ }^{2}$ They found an arterial (arterialized capillary sample) to end-tidal gradient, (a-ET) $\mathrm{PCO}_{2}$, of 
$2.4 \mathrm{mmHg}$ in normal newborn infants, $3.5 \mathrm{mmHg}$ in preterm infants recovering from respiratory distress syndrome (RDS) and $9 \mathrm{mmHg}$ in preterm infants with bronchopulmonary dysplasia. ${ }^{2}$ The correlation between $\mathrm{PaCO}_{2}$ and $\mathrm{PETCO}_{2}$ was good in infants with healthy lungs, ${ }^{2}$ though the correlation was not good in infants who are critically ill. ${ }^{3,4}$ McCann et al, however, used successfully (a-ET) $\mathrm{PCO}_{2}$ difference, where $\mathrm{PETCO}_{2}$ was sampled from nasal cavity, as a trend monitor to evaluate the improvement of pulmonary functions following therapy in critically ill infants with RDS. ${ }^{3}$

Second, Campbell et al. confirmed that negative (a-ET) $\mathrm{PCO}_{2}$ gradients occurred in children and may not be due to experimental errors. The incidence of negative (a-ET) $\mathrm{PCO}_{2}$ gradients is $12 \%$ in healthy adults, ${ }^{5}$ whereas the incidence may be higher (50\%) in pregnant patients, ${ }^{6,7}$ and children. ${ }^{1,8}$ Negative (a-ET) $\mathrm{PCO}_{2}$ values have also been observed during exercise. ${ }^{9}$ Although late emptying of well-perfused alveoli with higher $\mathrm{CO}_{2}$ tensions contribute to the occurrence of negative (a-ET) $\mathrm{PCO}_{2}$ gradients, there are other important factors which may result in the negative (a-ET) $\mathrm{PCO}_{2}$ values in infants and children. These include reduced functional residual capacity (FRC), increased $\mathrm{CO}_{2}$ production and better overall ventilation/perfusion $(\dot{V} / \dot{Q})$ matching. These factors also result in negative (a-ET) $\mathrm{PCO}_{2}$ values in pregnant patients. ${ }^{6,7}$ Fluctuations in $\mathrm{PACO}_{2}$ (alveolar $\mathrm{CO}_{2}$ ) during the respiratory cycle determine the absolute values of $\mathrm{PeTCO}_{2}$, with the PeTCO 2 being close to peak $\mathrm{PACO}_{2}$ and the $\mathrm{PaCO}_{2}$ being close to mean $\mathrm{PACO}_{2}$. Fluctuations in $\mathrm{PACO}_{2}$ become exaggerated with increased $\mathrm{CO}_{2}$ production to reduce FRC. This results in an increase of $\mathrm{PACO}_{2}$ to the level of $\mathrm{PvCO}_{2}$ (mixed venous $\mathrm{CO}_{2}$ ), as a large amount of $\mathrm{CO}_{2}$ is evolved into a lung which becomes smaller as expiration continues. When dead space and $\dot{V} / \dot{Q}$ mismatch are minimized, as in infants and children with normal lungs and circulation, the changes of $\mathrm{PETCO}_{2}$ exceeding $\mathrm{PaCO}_{2}$ are increased. ${ }^{6-12}$ The presence of lung areas with increased time constants (i.e., alveoli with higher $\mathrm{PACO}_{2}$ emptying last) may further increase the chances of negative (a-ET) $\mathrm{PCO}_{2}$ gradient.

\section{K. Bhavani-Shankar MD \\ Metrowest Medical Center \\ Framington, MA 01701.}

\section{REFERENCES}

1 Campbell FA, McLeod ME, Bissonnette B, Swartz JS.

End-tidal carbon dioxide measurement in infants and children during and after general anaesthesia. Can $\mathbf{J}$ Anaesth 1994; 41: 107-10.

2 Dumpit FM, Brady JP. A simple technique for measuring alveolar $\mathrm{CO}_{2}$ in infants. J Appl Physiol 1978; 45: 648-50.

3 McCann EM, Lewis K, Deming DD, Donovan MJ, Brady $J P$. Controlled trial of furosemide therapy in infants with chronic lung disease. The Journal of Pediatrics 1985; 106: 957-62.

4 Hand IL, Shepard EK, Kruass AN, Auld PA.

Discrepancies between transcutaneous and end-tidal carbon dioxide monitoring in the critically ill neonate with respiratory distress syndrome. Crit Care Med 1989; 17: 556-9.

5 Fletcher $R$, Jonson B. Deadspace and the single breath test for carbon dioxide during anaesthesia and artificial ventilation. Effects of tidal volume and frequency of respiration. Br J Anaesth 1984; 56: 109-19.

6 Shankar KB, Moseley H, Kumar Y, Vemula V. Arterial to end-tidal carbon dioxide tension difference during Caesarean section anaesthesia. Anaesthesia 1986; 41: 698-702.

7 Shankar KB, Moseley H, Kumar Y, Vemula V, Krishnan $A$. Arterial to end-tidal carbon dioxide tension difference during anaesthesia for tubal ligations. Anaesthesia 1987; 42: 482-6.

8 Rich GF, Sconzo JM. Continuous end-tidal $\mathrm{CO}_{2}$ sampling within the proximal endotracheal tube estimates arterial $\mathrm{CO}_{2}$ tension in infants. Can J Anaesth 1991; 38: 201-3.

9 Jones $N L$, Robertson DG, Kane JW. Differences between end-tidal and arterial $\mathrm{PCO}_{2}$ in exercise. $\mathrm{J}$ Appl Physiol 1979; 47: 954-60.

10 Bhavani Shankar K, Moseley H, Kumar AY, Delph Y. Capnometry and anaesthesia. Can J Anaesth 1992; 39 617-32.

11 Shankar KB, Moseley $H$, Kumar $Y$. Negative arterial to end-tidal gradients (Letter). Can J Anaesth 1991; 38: 260-1.

12 Moorthy SS, Losasso AM, Wilcox J. End-tidal $\mathrm{PCO}_{2}$ greater than $\mathrm{PaCO}_{2}$. Crit Care Med 1984; 12: 534-5.

\section{Co-axial placement of endobronchial blocker}

To the Editor:

An 8-14 Fogarty occlusion catheter (Baxter Healthcare Corporation, Santa Ana, CA) has been used to achieve endobronchial blockade for one lung anesthesia, ${ }^{1}$ and the technique has been modified to place the Fogarty catheter coaxially using a fibreoptic bronchoscope and two bronchoscopic airway connectors placed in series. ${ }^{2}$ However, positioning under direct fibreoptic vision can be difficult. We report a modification of these techniques to place the 8-14 Fogarty catheter coaxially as an endobronchial blocker by selectively intubating a mainstem bronchus, advancing a blocker through the endotracheal tube, and then withdrawing the tube into the trachea. 